\title{
Evaluation of Intussusceptions in Under - Five Children in Aba Nigeria
}

\author{
Samuel Chidi Ekpemo", ${ }^{1,}$ Emeka Nkwo \\ ${ }^{1}$ Department of Surgery, Abia State University, Aba, Nigeria \\ ${ }^{2}$ Department of Obstetrics and Gynaecology, Federal Medical Centre, Umuahia, Nigeria
}

Email address:

chidisamuelekpemo@gmail.com (S. C. Ekpemo)

${ }^{*}$ Corresponding author

To cite this article:

Samuel Chidi Ekpemo, Emeka Nkwo. Evaluation of Intussusceptions in Under - Five Children in Aba Nigeriaa. American Journal of Pediatrics. Vol. 5, No. 1, 2019, pp. 18-21. doi: 10.11648/j.ajp.20190501.14

Received: January 15, 2019; Accepted: February 18, 2019; Published: March 11, 2019

\begin{abstract}
Background: Intussusception remains a common cause of intestinal obstruction in infants and children. The operative treatment remains the main stay of treatment due to late presentation, long referral chain, paucity of knowledge about the disease condition by midwife and doctors. This study is intended to ascertain the pattern of presentation, management and outcome. Method: This is a prospective study of 48 children that was managed for intussusceptions at the Abia State University Teaching Hospital from November 2016 t0 November 2018. Structured proforma was opened for demography, clinical presentation, investigation, treatment modalities and outcome. Data was analysed using SPSS version 17 for proportions and percentages. Results: There were 24 boys and 24 girls aged 3 months to 13 months with a mean of 8 months. The median duration of symptoms onset and presentation was 4 days $\{1$ day to 14 days $\}$. Thirty-six patients $\{75 \%\}$ presented after 48 hours of onset of symptoms. A classic triad \{bilious vomiting, bloody mucoid stool and abdominal mass $\}$ was present in over 40 patients $\{83 \%\}$. Ten patients did not pass bloody mucoid stool. Thirty patients $\{62.5 \%\}$ had predisposing factors which included gastroenteritis and/or respiratory tract infection. 8 patients had hydrostatic saline reduction under ultrasound with success in six patients. Forty-two patients were operated $\{40$ patients primarily and 2 patients following failed hydrostatic reduction\}. Twenty-eight patients had resection and anatomises of ileocolic segment due to gangrenous bowel. Fourteen patients had manual reduction of intussuception with healthy bowel. Mortality was $8.3 \%$ \{4 patients $\}$ from overwhelming sepsis and respiratory distress. Twenty patients had surgical site infection and 4 patients had incisional hernias. Conclusion: Late presentation was high in this series, however, emphasis on health education of mothers during antenatal visit that passage bloody mucoid stool by their child needs evaluation by a paediatrician will reduce late presentation morbidity and mortality in our patients.
\end{abstract}

Keywords: Intussusceptions, Under-Five Children, Evaluation

\section{Introduction}

Intussusception remains a common cause of intestinal obstruction in infants and children. The invagination of a part of the bowel into another distal portion is one of the most common causes of intestinal obstruction. The most frequent anatomic presentation is invagination of the terminal ileum into the colon, but colocolic and ileoileal intussusception are not uncommon [1]. Common clinical features include abdominal pain, colic, bilious vomiting, progressive abdominal distension, rectal bleeding and palpable abdominal mass. The aetiology of intussusception is unknown, with an anatomic cause identified in $10 \%$ of cases. The majority of cases occur in children less than 2 years of age, the so-called "idiopathic" group. In this cohort, intussusception often occurs after respiratory or gastrointestinal infection (diarrhoea) in younger children. In older children, intussusception occurs much less commonly but may result from an anatomic abnormality that forms a "lead point" or predisposing condition (eg, lymph node, lymphoma, intestinal polyp or tumour, Meckel's diverticulum. [2] The operative treatment remains the main stay of treatment due to late presentation, longer referral 
chain, paucity of knowledge about the disease condition by midwife and doctors. This study is intended to ascertain the pattern of presentation, management and outcome of intussusceptions at the Abia State University Teaching Hospital Aba Nigeria.

\section{Methodology}

This is a prospective study of 48 children that was managed for intussusceptions at the Abia State University Teaching Hospital Aba Nigeria from November 2016 to November 2018. Structured proforma was opened for demography, clinical presentation, investigation, treatment modalities and outcome. Data was analysed using SPSS version 17 for proportions and percentages.

\section{Results}

\subsection{Demography}

There were 24 boys and 24 girls with male to female ratio (1:1). The age range was from 3 months to 13 months with a peak incidence between 6-12 months. Twenty-eight patients were within 6-12 months age group as shown in Table 1.

Table 1. Age at presentation in months.

\begin{tabular}{lll}
\hline Age in months & Number of patients & Percentage \\
\hline 1-5months & 16 & 33 \\
6-12months & 28 & 58 \\
$>12$ months & 4 & 8 \\
\hline
\end{tabular}

The peak month of the year was November where eight patients $(16 \%)$ were treated for intussusceptions as shown in Table 2.

Table 2. Month of the year the patient presented.

\begin{tabular}{lll}
\hline Month of the year & Number of patients & Percentage \\
\hline Januarary & 0 & 0 \\
February & 2 & 4 \\
March & 4 & 8 \\
April & 0 & 0 \\
May & 6 & 13 \\
June & 4 & 8 \\
July & 6 & 13 \\
August & 6 & 13 \\
September & 2 & 4 \\
October & 4 & 8 \\
November & 8 & 16 \\
December & 0 & 0 \\
\hline
\end{tabular}

\subsection{Clinical Features}

Thirty-six patients (75\%) presented after 48hours of onset of symptoms as shown in Table 3. The median duration of symptoms onset and presentation was 4 days (1 day to 14days).
Table 3. Duration of symptoms before presentation.

\begin{tabular}{lll}
\hline Duration in days & Number of patients & Percentage \\
\hline 1 & 2 & 4 \\
2 & 10 & 21 \\
3 & 6 & 13 \\
4 & 8 & 17 \\
5 & 19 & 40 \\
6 & 0 & 0 \\
7 & 8 & 17 \\
\hline
\end{tabular}

Table 4. Duration of symptoms from presentation to surgery.

\begin{tabular}{lll}
\hline Duration in hours & Number of patients & Percentage \\
\hline $1-4$ & 20 & 42 \\
$5-8$ & 20 & 42 \\
$9-12$ & 8 & 16 \\
\hline
\end{tabular}

A classic triad \{bilious vomiting, bloody mucoid stool and abdominal mass $\}$ was present in over 40 patients $(83 \%)$. Ten patients $(21 \%)$ did not pass bloody mucoid stool. Thirty patients $(62.5 \%)$ had predisposing factors which included gastroenteritis and/or respiratory tract infection

Table 5. Clinical presentation.

\begin{tabular}{lll}
\hline Clinical presentation & Number of patients & Percentage \\
\hline Abdominal pain & 44 & 92 \\
Bilious Vomiting & 44 & 92 \\
Fever & 42 & 88 \\
Bloody stool & 40 & 83 \\
Diarrhoea & 32 & 67 \\
Constipation & 40 & 83 \\
Abdominal mass & 40 & 83 \\
Dehydration & 36 & 75 \\
Shock & 20 & 42 \\
Absent bowel sound & 36 & 75 \\
Palpable rectal mass & 14 & 29 \\
Prolapse & 4 & 8 \\
\hline
\end{tabular}

\subsection{Investigation}

Abdominal ultrasound is highly accurate in the diagnosis of intussusceptions in 40 patients $(83 \%)$ in this series.

\subsection{Treatment Modality}

Eight patients had hydrostatic saline reduction under ultrasound with success in six patients. Forty-four patients were operated (40 patients primarily and 2 patients following failed hydrostatic reduction). Twenty-eight patients had resection and anatomises of ileocolic segment due to gangrenous bowel. Fourteen patients had manual reduction of intussusceptions with healthy bowel as shown in Table 6 .

Table 6. Method of treatment.

\begin{tabular}{lll}
\hline Method of treatment & Number of patients & Percentage \\
\hline Laporotomy & 42 & 88 \\
Manual reduction & 14 & 33 \\
Resection and anatomises & 28 & 67 \\
Hydrostatic reduction & 6 & 12 \\
Reduced at surgery & 0 & 0 \\
\hline
\end{tabular}

\subsection{Outcome}

Mortality was $8.3 \%$ (4 patients) from overwhelming sepsis 
and respiratory distress. Twenty patients had surgical site infection and 4 patients had incisional hernias.

\section{Discussion}

The management of intussusceptions has progressed universally from surgical reduction to the use of hydrostatic and pneumatic reduction for the acute and uncomplicated cases. However, the process has been hindered in developing countries, especially in the sub-Saharan Africa, due to late presentation, inadequate facilities and expertise to manage these patients non-operatively

The peak age incidence was in infants aged 6-12 months. This is similar to the findings in previous studies [4-6]. However, a similar study among Taiwanese children reported peak age in children 1 to 3 years [7]. All these cases were in under-five children who are known to be the highest contributor to mortality in developing countries. Males were equally affected compared to their female counterparts in this series which is in contrast to male preponderance reported by other workers [8-9]. Seasonal variations in the occurrence of intussusceptions remain controversial; while some workers have reported some variations or no variation. Findings from the current study show that majority of cases occurred in the month of November which corresponds to the rotavirus diarrhoeal season [10]

The average duration of symptoms prior to presentation was 4.1 days (range 10 hours to 8 days). Other studies in Nigeria [11] and elsewhere in sub-Saharan Africa [12] have reported similar findings. This late presentation will ultimately affect the clinical outcome either in terms of morbidity and/or mortality [13]. This probably explains the observation of late presentation in majority of the cases studied with its attendant risks. Late presentations may arise mainly from ignorance, misconceptions, poverty and poor access to tertiary health care. This may lead to selfmedication and patronage of patent medicine dealers making caregivers to present only when their expectations are not the obvious.

The common clinical presentations were vomiting, fever, passage of red currant stools, diarrhoea, abnormal/ absent bowel sounds and abdominal distension as shown in Table 5. Similar findings have been reported by other researchers [1415]. It follows that due to ignorance some of the caregivers may not know when the red-line is crossed in terms of acute diarrhoea which they mostly attribute to "teething" especially in infants and acute intestinal obstruction like intussusceptions as most of them may first try selfmedications including herbal concussions at home.

Abdominal ultrasound was the main radiological modality for the diagnosis of intussusceptions in over $90 \%$ of the cases in this series. It has the clear advantage of being highly accurate in diagnosing intussusceptions, monitoring the reduction process as well as in evaluating post-reduction residual intussusceptions and possible lead points [16]. Another positive factor of ultrasound is its widespread use among paediatric institutions but it is the lack of ionizing radiation that is its most important advantage over all X-ray methods [17].

Majority of the cases in our series had explorative laparotomy for manual or resection and anatomises for their intussusceptions. This might be as a result of their late presentation resulting in complications with possibility of failure of other conservative methods of treatment like hydrostatic reduction. Higher rates of surgery lead to higher medical costs and longer median hospital stay [28] as seen in the current studies.

The case fatality rate observed was $8.3 \%$ in the series which is comparable to 5.0 reported by Tagbo et al in Enugu Nigeria but lower than $23 \%$ reported by Adejuigbe et al at Ile Ife, Nigeria.

\section{Conclusion}

Intussusception is a leading cause of death of under- five children in Nigeria and other countries in sub-Saharan Africa. Late presentation was high in this series increasing the morbidity and mortality. Health education of mothers during antenatal visit that passage of bloody mucoid stool by their child needs evaluation by a paediatric surgeon. Health insurance to reduce cost of treatment, proper training of doctors and manpower development will in long way reduce late presentation, morbidity and mortality in our patients.

\section{References}

[1] Shally Awasthi, Girdhar G Agarwal, Vikas Mishra, Vijay Laxmi Nag. Four-country surveillance of intestinal intussusception and diarrhoea in children. Journal of Paediatrics and Child Health. 2009: 45; 82-8.

[2] Tate JE, Mweda JM, Armah B, Jani B. Evaluation of Intussusception after Monovalent Rotavirus Vaccination in Africa. N Engl J Med 2018; 378: 1521-8.

[3] Atalabi, OM, Ogundoyin, OO, Ogunlana, DI, Onasanya, OM, Lawal, TA, Olarinoye, AS. Hydrostatic reduction of intussusception under ultrasound guidance: An initial experience in a developing country. Afr J Paediatr Surg 2007; 4 (2): 68-71.

[4] Ekenze SO, Mgbor SO Childhood intussusception: the implications of delayed presentation. Afr J Paediatr Surg 2011 8: 15-18.

[5] Archibong AE, Usoro IN, Ikpi E, Inyang A (2001) Paediatric intussusception in Calabar, Nigeria. East Afr Med J 78: 19-21. 15.

[6] Bode CO Presentation and management outcome of childhood intussusception in Lagos: a prospective study. Afr J Paediatr Surg2008 5: 24-28. 16.

[7] HO, W. L., Yang, T. W., Chi, W. C., Chang, H. J., Huang, L. M. and Chang, M. H. Intussusception in Taiwanese Children: Analysis of Incidence, Length of Hospitalization and Hospital Costs in Different Age Groups. Journal of the Formosan Medical Association, 2005: 104, 398-40.

[8] Lai AH, Phua KB, Teo EL Jacobsen AS. Intussusception: a three-year review. Ann Acad Med Singapore 2002: 31; 81-85. 
[9] Crankson SJ, Al-Rabeeah AA, Fischer JD, Al-JadaanSA, NamshanMA. Idiopathic intussusception in infancy and childhood. Saudi Med J 2003: 24; S18-S20.

[10] Tagbo, B. N., Mwenda, J. M., Armaha, Obidike, E. O., Okafor, H. U., Oguonu, T., et al. Epidemiology of Rotavirus Diarrhoea among Children Younger than 5 Years in Enugu, South East Nigeria. Pediatric Infectious Disease Journal. 2014: 33; S19-S22.

[11] Ameh EA The morbidity and mortality of laparotomy for uncomplicated intussusception in children. West Afr J Med2002: 21; 115-116.

[12] Carneiro PM, Kisusi DM Intussusception in children seen at Muhimbili National Hospital, Dar es Salaam. East Afr Med J 2004: 81; 439-442.

[13] Ameh EA The morbidity and mortality of right hemicolectomy for complicated intussusception in infants. Niger Postgrad Med J 2002: 9; 123-124.
[14] Adejuigbe, O., Jeje, E. A. and Owa, J. A. Childhood Intussusception in Ile-Ife, Nigeria. Annals of Tropical Paediatrics International Child Health. 1991: 11; 123-12.

[15] Beckie Nnenna Tagbo, Jason Mwenda, Christopher Eke, Tagbo Oguonu Sebastin Ekenze. Retrospective Evaluation of Intussusception in Under-Five Children in Nigeria. World Journal of Vaccines. 2014: 4; 123-132.

[16] Stringer MD, Capps SW, Pablot SM. Sonographic detection of the lead point in intussusception. Arch Dis Child 1992: 67; 529-530.

[17] Pracros JP, Tran-Minh VA, Morin DE, et al. Acute intestinal intussusception in children: contribution of ultrasonography (145 cases). Ann Radiol 1987: 30; 525-530.

[18] Ogubdoyin OO, Atalabt OM, Lawal TA, Olulana DI. Experience With Sonogram-Guided Hydrostatic Reduction of Intussusception in Children in South-West Nigeria JWACS 2013: 3; 2, 4-6. 